\title{
Editorial-Embracing How Scholarly Publishing Can Build a New Research Culture, Post-COVID-19
}

\author{
Gemma E. Derrick \\ Centre for Higher Education Research \& Evaluation, Lancaster University, Lancaster LA1 4YD, UK; \\ g.derrick@lancaster.ac.uk
}

Received: 15 May 2020; Accepted: 18 May 2020; Published: 19 May 2020

It is an absolute pleasure to be writing this, my first Editorial as Editor in Chief for Publications. What a time to be taking on this role-mid-COVID-19 lockdown. I take the reins as Editor-in-chief from the amazing Dr Tony Ross-Hellauer at an extremely challenging, but exciting time.

With this in mind and before I go any further, may I just say how fortunate I am in this role to have the support of an outstanding team of Editors and Editorial Board members. The role of individuals working together as a community, and the benefits it brings, should not be under-estimated in our emerging post-COVID-19 world. Each member of the Publications Editorial team brings a wealth and variety of perspectives that cements its reputation for fostering high-quality, relevant research in full accordance with the principles of open science. Principles which, as we are increasingly becoming aware, are vitally important mid- and post-COVID-19.

I am not going to use the word 'unprecedented' as this seems to be an overused term of late but it goes without saying that the forthcoming years will be extremely challenging for academia, and scholarly publishing in general. If nothing else, the COVID-19 crisis has highlighted how some starkly chronic problems in the research environment operated. The effects of lockdown and the effects that arise as we transition into the new, post-COVID life will only further exacerbate these issues in research, the way we work together within academia, and how we co-ordinate with our non-academic stakeholders. These issues highlight the importance of open science as a way to provide insights to policymakers hoping to tackle this crisis and a general public hungry for answers. However, alongside a continued commitment to open science comes something more fundamental and that is the realization that our value comes, not as individual providers of research, but by being members of a community. As we adjust to a new/post-normal comes the opportunity to envision new ways of working, ways that put 'kindness' at the centre of our research practice. If nothing else, the immediate reactions to the COVID-19 crisis demonstrate that research kindness is possible, and we can now ensure that these and other acts of kindness are not just temporary [1].

As a journal, we already enforce a "rigorous peer review system" and "enforce strict ethical policies and standards" of all our papers and strive to foster a culture of the promotion of high-quality research articles. However, although these words send a signal of strength and non-negotiable standard, what is needed is a realization that the role of the academic journal within our community can be more than just a publisher of research results but can also act to instigate real change in research culture.

So, this is a call to arms, if you like, to be kinder, more supportive and engage in a more formative way of learning that benefits all members of our community. As an open access, academic journal, we can make a large difference in constructing the type of academic community we want. This is through practicing a commitment to excellence, yes, but also a commitment to research kindness. 'Kindness' is a very broad term that goes beyond simply not acting like a douchebag. It is the realization and corresponding actions that encompass a commitment to the principles of equity, the belief in the benefits of diversity, the promise to foster the development of others above and beyond our own selfish ambitions and understanding our role as research leaders within our community. What counts 
is not our own promotion, but how we foster the development of each other and promote our strengths as a community.

In the coming months, Publications will strive to envision ways of working to embed a culture of kindness. Notably, this will happen through our peer review process, where it will no longer just provide decisions but also provide formative feedback to assist authors to improve their manuscripts. This will involve, at the very least, a change in how we structure our templates for peer review, as well as the guidelines offered to guide peer reviewers in their assessment and provision of advice. To be kind is not to be weak, and we will continue to support a rigorous peer review process and demand a high quality in the research, but we will do so recognizing that high quality comes after the provision of high-quality feedback and support of the author's development of the rigorous research manuscripts.

I will be speaking with many of my editorial board about how we at Publications can work towards this goal. I am also open to receiving other ideas from others about how we can provide a more formative peer review process. I hope that with this small change with our practices, we can build a kinder, more reflective post-COVID research culture.

Conflicts of Interest: The author declares no conflict of interest.

\section{References}

1. Derrick, G.E. How COVID-19 lockdowns could lead to a kinder research culture. Nature 2020, 581, 107-108. [CrossRef] [PubMed]

(C) 2020 by the author. Licensee MDPI, Basel, Switzerland. This article is an open access article distributed under the terms and conditions of the Creative Commons Attribution (CC BY) license (http://creativecommons.org/licenses/by/4.0/). 